\title{
O produtivismo acadêmico na vida dos discentes de pós-graduação
}

\author{
Letícia Silvana dos Santos Estácio \\ Mestre; Universidade Federal de Santa Catarina, Florianópolis, SC, Brasil \\ leticiasestacio@gmail.com \\ Wemylinn Giovana Florêncio Andrade \\ Mestre; Universidade Federal de Santa Catarina, Florianópolis, SC, Brasil \\ wemylinn@gmail.com \\ Vinícius Medina Kern \\ Doutor; Universidade Federal de Santa Catarina, Florianópolis, SC, Brasil \\ v.m.kern@gmail.com \\ Cristiano José Castro de Almeida Cunha \\ Doutor; Universidade Federal de Santa Catarina, Florianópolis, SC, Brasil \\ cunha@egc.ufsc.br
}

\begin{abstract}
Resumo: O produtivismo acadêmico é um fenômeno caracterizado pela excessiva valorização da quantidade e pela escassa consideração da qualidade da produção acadêmica. O objetivo deste artigo é compreender a influência do produtivismo acadêmico na vida dos discentes de um curso de pós-graduação a partir de suas percepções. O estudo utilizou o método qualitativo fundamentado na entrevista em profundidade e na análise temática dos dados. Foram entrevistados dez discentes. Os discentes consideram o produtivismo acadêmico tanto positivo quanto negativo. Do ponto de vista positivo, argumentam que a cobrança por produzir contribui no processo de construção do conhecimento, e do lado negativo, que a pressão para publicar em quantidade exige intensa dedicação, gerando, em muitos casos, problemas psicológicos, emocionais e físicos.
\end{abstract}

Palavras-chave: Produtivismo acadêmico. Pós-Graduação. Produção científica. Discentes.

\section{Introdução}

Inicialmente, deve-se deixar claro que os termos produtivismo acadêmico e produção científica são coisas diferentes, visto que o produtivismo caracterizase como uma pressão e/ou estímulo à produção, o que poderia ser válido se produzir cientificamente fosse uma mercadoria e não trabalho intelectual de altíssimo nível.

Vale também ressaltar que produzir muito conhecimento científico não é considerado produtivismo, uma vez que existem autores altamente produtivos 
com elevado nível de qualidade, ao contrário do produtivismo, que visa focar só em quantidade, sem levar em consideração a qualidade do que foi produzido. Muitas vezes, a produção acadêmica é considerada superficial, de modo que sua finalidade consiste apenas em cumprir exigências determinadas pelas normas (ZANDONÁ; CABRAL; SULZBACH, 2014). Brembs (2018) reforça ao dizer que o uso da produtividade como critério de seleção na contratação, promoção e financiamento cria grande pressão, e leva a uma maior frequência de práticas de pesquisa questionáveis e resultados falsos.

Nesse sentido, Sguissardi (2010) explica que, derivado dos processos de avaliação da pós-graduação, o produtivismo acadêmico é compreendido como um fenômeno caracterizado pela excessiva valorização da quantidade de produção científica gerada no âmbito acadêmico e pela escassa atenção à sua qualidade, à formação e ao bem-estar dos pesquisadores.

Diante do exposto, a marca da competitividade nos programas de pósgraduação e na vida profissional dos pesquisadores, docentes ou discentes deuse por meio de uma regulação da Coordenação de Aperfeiçoamento de Pessoal de Nível Superior (CAPES) voltada à formação de pesquisadores a partir de 1990. Desse modo, os programas de pós-graduação passaram por profundas mudanças na sua forma de financiamento, gestão e avaliação, as quais afetaram pesquisadores e a própria qualidade da produção do conhecimento (BIANCHETTI, 2009).

O sistema de avaliação dos programas de pós-graduação, para muitos, contribui para melhorar o desempenho dos programas e é considerado positivo. No entanto, a pressão pelo cumprimento das metas também gera um grande desafio para a comunidade científica, inclusive para os discentes, o que colabora para o surgimento de problemas sociais, físicos e mentais. As metas podem incluir, por exemplo, a exigência de que mestrandos e doutorandos submetam artigos em seu primeiro ano de curso junto a seu orientador e que os periódicos científicos da área sejam acima do estrato Qualis B2.

O objetivo deste estudo é compreender o produtivismo acadêmico com base nas experiências de vida dos discentes de um curso de pós-graduação. Os 
objetivos específicos são: (1) descrever a percepção dos discentes sobre o produtivismo acadêmico na pós-graduação; (2) identificar, nos discursos dos discentes, impactos do produtivismo acadêmico.

O estudo foi realizado no Programa de Pós-Graduação em Ciência da Informação da Universidade Federal de Santa Catarina (PPGIN/UFSC). A escolha pelo programa se deu pela facilidade do contato com boa parte dos discentes matriculados em seus respectivos cursos de mestrado e doutorado. $\mathrm{O}$ trabalho apresenta a seguinte estrutura: apresentação dos procedimentos metodológicos aplicados na pesquisa; descrição dos aspectos teóricos; análise e discussão dos resultados; e considerações finais.

\section{Metodologia}

Esta pesquisa é exploratória, pois visa criar familiaridade acerca de um fato ou fenômeno por meio da prospecção de materiais que possam informar ao pesquisador a verdadeira importância do problema, o estágio em que se encontram as informações já disponíveis sobre o assunto e revelar novas fontes de informação (SANTOS, 2000). Com o objetivo de compreender o produtivismo acadêmico, com base nas experiências de vida dos discentes de um curso de pós-graduação, adotou-se o método qualitativo de pesquisa. Em seu mais amplo sentido, a pesquisa qualitativa representa uma investigação que produz dados descritivos: palavras faladas ou escritas e comportamentos observados (TAYLOR; BOGDAN, 1998).

Para a coleta dos dados, utilizou-se a técnica de entrevistas individuais em profundidade. Sob a ótica de Taylor e Bogdan, essa técnica consiste em "[...] encontros cara a cara entre o investigador e o informante, dirigidos para a compreensão das perspectivas que o informante tem a respeito de sua vida, experiências ou situações expressadas com suas próprias palavras.” (1998, p. 101, tradução nossa). Esse tipo de entrevista permite que o entrevistador se insira no mundo mental dos envolvidos. Com essa técnica, o pesquisador adquire uma compreensão profunda das perspectivas dos informantes, 
principalmente em relação às suas experiências de vida, valores, crenças e opiniões (TAYLOR; BOGDAN, 1998).

O planejamento de perguntas capaz de atingir o objetivo pretendido foi elaborado por meio do instrumento denominado roteiro. Além de coletar informações básicas, o roteiro serviu como um meio para o entrevistador se organizar para o processo de interação com o entrevistado. $\mathrm{O}$ roteiro foi composto pela seguinte pergunta: Qual a sua percepção quanto ao produtivismo acadêmico com base nas experiências que vivenciou na pós-graduação?

Ressaltamos que foi realizado um pré-teste com um discente do programa de pós-graduação que não fazia parte dos entrevistados que iriam compor a amostra da pesquisa. Suas contribuições permitiram que a pergunta elaborada permanecesse, visto que, gerava bastante discussão, ajudando, dessa forma, no desenvolvimento da pesquisa.

Foram entrevistados dez discentes do Programa de Pós-Graduação em Ciência da Informação da Universidade Federal de Santa Catarina (PPGCIN/UFSC). As entrevistas foram realizadas no mês de setembro de 2016, de forma presencial, em locais escolhidos pelos participantes. Todas foram gravadas em áudio (através de um aparelho de telefone celular) e transcritas, respeitando a oralidade dos entrevistados. Antes das entrevistas, houve uma conversa inicial com cada entrevistado. De acordo com Minayo (2010), essa conversa tem por objetivo "quebrar o gelo" e criar um clima mais descontraído.

A escolha por esses discentes deu-se em razão de frequentarem diariamente os laboratórios de estudo do PPGCIN/UFSC, próximos ao laboratório das autoras desta pesquisa, o que permitiu o contato entre entrevistado e entrevistador. Para preservar a identidade dos discentes, seus nomes não são revelados.

Com o objetivo de encontrar um sentido para os dados coletados, utilizou-se a análise temática (MINAYO, 2007). Para Minayo, “A análise temática consiste em descobrir os núcleos de sentido que compõem uma comunicação cuja presença ou frequência signifique alguma coisa para o 
objetivo analítico visado." (MINAYO, 2007, p. 316). De acordo com a autora, operacionalmente, ela ocorre em três fases:

a) Pré-análise: organização do que vai ser analisado; exploração do material por meio de várias leituras; também é chamada de "leitura flutuante"; b) Exploração do material: é o momento em que se codifica o material; primeiro, faz-se um recorte do texto; após, escolhem-se regras de contagem; e, por último, classificam-se e agregam-se os dados, organizando-os em categorias teóricas ou empíricas; c) Tratamento dos resultados: nesta fase, trabalham-se os dados brutos, permitindo destaque para as informações obtidas, as quais serão interpretadas à luz do quadro. (MINAYO, 2007, p.316)

O Programa de PPGCIN/UFSC surgiu no ano 2000 com a criação do curso de mestrado. Treze anos depois, é criado o curso de doutorado. O programa de pós-graduação está localizado no Centro de Ciências da Educação (CED). Pertence à área de Comunicação e Informação da CAPES, como modelo de regime letivo trimestral, conceito CAPES 5 e com área de concentração em Gestão da Informação. Essa área “[...] visa enfatizar o estudo dos fenômenos relacionados aos processos centrais da gestão da informação, na perspectiva de localizar estes fenômenos, explorá-los, compreendê-los e explicá-los." (UNIVERSIDADE FEDERAL DE SANTA CATARINA, 2017, doc. não paginado).

Atualmente, o PPGCIN/UFSC conta com 38 discentes regulares no mestrado, 42 no doutorado e um no pós-doutorado. Sendo assim, o universo da pesquisa é composto por 80 discentes regularmente matriculados nos cursos de mestrado, doutorado e pós-doutorado no PPGCIN/UFSC. Dessa soma, selecionou-se uma amostra para a coleta de dados, do tipo intencional e não probabilística.

\section{Aspectos teóricos}

Com a intenção de propor uma explanação objetiva e racional da realidade, Japiassú e Marcondes (2001) afirmam que a ciência estabelece uma categoria formada por um conjunto de aquisições intelectuais. Na visão de Targino 
(2000), a ciência é considerada uma instituição social, dinâmica, contínua e cumulativa, tendo por finalidade desvendar e compreender a natureza e seus fenômenos por meio de metodologias seguras e sistemáticas. Além disso, a ciência deve estar amparada por um arcabouço teórico, no qual estarão presentes todas as teorias que fundamentam o desenvolvimento da pesquisa, descrevendo, por sua vez, todas as suas etapas, objetivos e resultados.

A ciência é uma atividade social desenvolvida por diversos grupos de indivíduos e instituições que objetivam realizar novas descobertas científicas e gerar novos conhecimentos.

O conhecimento científico é entendido por Leite (2006, p. 48) como o conjunto de:

[...] saberes baseados na experiência, proveniente das atividades de pesquisa, e na informação científica, natural do ambiente acadêmico, contextual e relacional, composta de duas vertentes: a tácita, própria do indivíduo, proveniente da experiência, relacionada às habilidades e competências, parte de sua estrutura cognitiva, portanto subjetiva; e a explícita (ou codificada), externa ao indivíduo (informação), proveniente da externalização do conhecimento tácito.

As universidades constituem um dos motores do desenvolvimento do conhecimento (KUNZ, 2012) que ocorre em vários espaços (programas de pósgraduação stricto sensu; pós-graduação lato sensu; atividades de iniciação científica) e assume diferentes formas (trabalhos finais de graduação; publicação de dissertações; teses; livros; artigos).

A produção científica é um resultado importante para as universidades, pois representa uma contribuição relevante para o desenvolvimento da sociedade. Em decorrência dessa característica, nas últimas décadas, a produção científica "[...] passou a ser fortemente utilizada como mecanismo de atribuição de mérito acadêmico, em que a relevância dos trabalhos é aferida por intermédio de medidas bibliométricas." (SILVA; SILVA; MOREIRA, 2014, p. 1427).

No Brasil, as instituiç̧̃̃es que produzem conhecimento lidam diretamente com agências que fomentam a pesquisa no país. Dentre essas agências, a CAPES tem "[...] sido decisiva para os êxitos alcançados pelo sistema nacional 
de pós-graduação, tanto no que diz respeito à consolidação do quadro atual, como na construção das mudanças que o avanço do conhecimento e as demandas da sociedade exigem.” (BRASIL, 2017, doc. não paginado). Além da CAPES, o CNPq (Conselho Nacional de Desenvolvimento Científico e Tecnológico) tem uma relação importante com os programas de pós-graduação. Sua principal atribuição é fomentar a pesquisa científica e tecnológica e incentivar a formação de pesquisadores brasileiros.

O sistema de avaliação da CAPES é orientado pela Diretoria de Avaliação CAPES e realizado com a participação da comunidade acadêmicocientífica por meio de consultores ad hoc. Estabelecida a partir de 1988, a avaliação é atividade essencial para assegurar e manter a qualidade dos cursos de Mestrado e Doutorado no país, tendo como objetivo avaliar os programas de pós-graduação; promover o acesso e divulgação da produção científica; subsidiar investimentos na formação de recursos de alto nível no país e exterior; colaborar com a cooperação científica internacional; induzir e fomentar a formação inicial e continuada de professores para a educação básica nos formatos presencial e a distância (BRASIL, 2017).

Diante do exposto, observa-se a necessidade desse sistema de avaliação analisar aspectos quantitativos e qualitativos, apresentando resultados que expressem indicadores de qualidade da educação, levando em conta a diversidade entre as áreas do conhecimento (GATTI, 2001). Realizada quadrienalmente pela CAPES, a avaliação da pós-graduação brasileira, utiliza, como parâmetros avaliativos, indicadores quantitativos extraídos de cada programa de pós-graduação (CASTANHA; GRÁCIO, 2014), os quais são avaliados pelos comitês que fazem recomendações sobre o conceito/nota/estrato.

Recentemente, no meio acadêmico, há uma onda produtivista que privilegia quantidade sobre qualidade. No entanto, vale ressaltar que os indicadores quantitativos apresentados pela CAPES apresentam relação com o registro do que é produzido pelos programas de pós-graduação, mas, necessariamente, não é o mesmo que o produtivismo. Shelton e Agger (2010) relacionam o produtivismo acadêmico ao fordismo, ou seja, Ford buscava o 
lucro praticando pequenas margens sobre grandes volumes, diferentemente da Rolls Royce, cujos carros eram feitos vagarosamente à mão, com alta qualidade e altas margens de lucro.

A imposição de novas regras criadas pelos programas de pós-graduação como a publicação de no mínimo um artigo por ano, artigos publicados em revistas com Qualis acima de B1, publicação de artigos para manutenção de bolsas de pesquisa, entre outras exigências, pouco afeta os indicadores gerados pela CAPES, e sim, confirma o produtivismo em troca de benefícios. Ou seja, ao adotar a prática produtivista é possível substituir um trabalho de qualidade por vários medíocres, nulos ou danosos.

Além disso, o ranking Qualis é inadequado para avaliar pessoas ou para selecionar revista para submissão de artigo, dado que inclui apenas revistas que contêm artigos publicados recentemente por docentes dos programas avaliados. O próprio website do Qualis alerta sobre usos indevidos e exclui a responsabilidade da CAPES e requer que o usuário marque um checkbox declarando que "Li o texto acima e entendi a finalidade do Qualis." (BRASIL, 2018). A diretora de Avaliação da CAPES tentou esclarecer o que é o Qualis e para que serve (BARATA, 2016). Apesar disso, a avaliação de docentes e discentes com base no Qualis vem-se tornando comum, reforçando uma cultura de produtivismo, submissão e a "[...] possibilidade do recurso à indução ou sobrevalorização de determinados periódicos [...]" (BARATA, 2016, p. 36).

De acordo com Frey (2003), o processo de produzir e publicar pelos estudantes torna-os, de um modo geral, prostitutas, uma vez que, a prostituição está em omitir o próprio pensamento em favor de algo que se crê "mais publicável". Barros (2014) reforça que, ao contrário de prostitutas que vendem seus corpos por dinheiro, os estudantes se vendem para estar de acordo com a vontade dos outros, a fim de obter uma vantagem.

Nesse contexto institucional, a cobrança e a pressão para publicar estão cada vez mais presentes no cotidiano dos pesquisadores, docentes e discentes. Para alguns autores, é justamente nesse momento que aumenta o número de pesquisadores “[...] que usam estratégias nada éticas para cumprir e superar 
metas. Entre estas estratégias está a autoria de artigos científicos em cuja elaboração, execução e redação não se teve uma participação efetiva." (DOMINGUES, 2013, p. 195).

No Brasil, tornaram-se recorrentes as críticas voltadas a esse sistema de avaliação imposto pelos programas de pós-graduação. Suas regras provocaram um fenômeno conhecido como 'produtivismo acadêmico', ou seja, “[...] o quantum de produção intelectual, sobretudo bibliográfica, desenvolvida num espaço de tempo específico, crescente de acordo com a qualificação acadêmica ('titulação') do professor/pesquisador.” (LUZ, 2005, p. 43). Para o autor, esse número corresponde ao necessário para que pesquisadores conservem e mantenham suas posições no campo científico.

Com origem nos Estados Unidos na década de 1950, o termo produtivismo acadêmico tornou-se mundialmente conhecido pela expressão publish or perish. Tanto pesquisadores quanto docentes que não publicassem conforme os parâmetros impostos pelas agências, pelas prerrogativas universitárias e pelo mercado, comprometeriam sua carreira profissional (FONSECA, 2001; NASCIMENTO, 2010; SGUISSARDI, 2010).

No Brasil, a adoção do produtivismo acadêmico ocorreu por volta de 1970, sendo legitimada nos anos 1990 (GODOI; XAVIER, 2012). Esse sistema compreende uma lógica de produção baseada na “[...] estratégia de sobrevivência pessoal e organizacional que fez da vida acadêmica algo muito distante do mundo e da prática intelectual.” (RICCI, 2009, p. 21). Em razão disso, muitas são as pessoas que associam o produtivismo acadêmico a uma lógica de mercado. Moreira (2009), por exemplo, reforça que a avaliação dos órgãos estatais transforma todo o processo de construção do conhecimento em mercadoria, colocando limites nos padrões de qualidade.

Segundo Godoi e Xavier (2012), o termo está associado a uma fábrica de fazer pontos. Ele é um "fetiche-conhecimento-mercadoria" que colabora para o “mal-estar" da academia brasileira (TREIN; RODRIGUES, 2011). 
A ênfase na quantidade produzida tem impactos significativos na qualidade do que se produz e na vida acadêmica e particular dos que fazem parte da comunidade científica (BIANCHETTI; VALLE, 2014), causando:

[...] complicações para a saúde [...] seja ela para a vida docente e discente [...], visto que patologias como gastrite, fadiga muscular e psíquica, dor nas costas e nas pernas, problemas na voz, insônia, estresse, tristeza profunda, e obesidade se tornam mais comuns. (FREITAS, 2013, p. 166).

Para Chauí (2003, p. 7), as universidades operam sob uma perspectiva que faz com que os discentes se curvem a exigências além do trabalho intelectual.

Mota e colaboradores reforçam que, além das complicações citadas acima, "A inserção dos estudantes no contexto da pesquisa e da extensão, promovendo certo exagero e exacerbação de tarefas acadêmicas, tem sido responsável pelo surgimento de sintomas característicos da Síndrome de Burnout." (MOTA et al., 2017, p. 246).

Consolidada por Maslach e Jackson (1981), a base teórica da Síndrome de Burnout envolve três componentes: exaustão emocional, despersonalização, realização profissional. Com base na teoria de Maslach e Jackson (1981), Mota et al. (2017, p. 245) caracterizam os três componentes sendo a (1) exaustão emocional "caracterizada por um sentimento muito forte de tensão emocional que produz sensação de esgotamento"; (2) a despersonalização é "resultado do desenvolvimento de sentimentos e de atitudes negativas"; e (3) a falta de realização profissional, caracteriza-se pela “[...] tendência de estar insatisfeito com as condições que afetam as habilidades interpessoais relacionadas com a prática profissional, influenciando, diretamente, a forma de atendimento e de contato com as pessoas [...]" (MOTA et al., 2017, p. 245). Em suma, a demanda de estudos, associada à concepção de sociedade, a qual está cada vez mais em rápida transformação, tende a ser uma das características deste fato.

Ainda, quanto ao produtivismo acadêmico, há aqueles que identificam pressupostos favoráveis e desfavoráveis. Patrus, Dantas e Shigaki (2015, p. 4-5) elencam alguns desses pressupostos favoráveis ao produtivismo: para Machado 
(2007) as exigências da CAPES têm por objetivo movimentar a ciência brasileira, instalar a cultura da pesquisa e da publicação no país, visto que o Brasil não tem a tradição da escrita. Além disso, muito dinheiro:

[...] público é investido no setor educacional superior; a CAPES entende que seja mais justo avaliar os programas de pós-graduação utilizando critérios quantitativos, pois os critérios qualitativos são mais suscetíveis às idiossincrasias, perspectivas e interesses das comissões de avaliadores. (PATRUS; DANTAS; SHIGAKI, 2015, p. 5).

Enfim, as publicações proporcionam visibilidade e prestígio aos pesquisadores (MEADOWS, 1999; MUELLER, 2007). Com relação aos pressupostos desfavoráveis, os autores supracitados (2015) consideram também que o produtivismo acadêmico acarreta sobrecarga do docente e do discente, podendo atingir a vida pessoal dos envolvidos e afetar a qualidade da produção. Nessa mesma linha, Hill (2003, p. 5) apresenta, como aspecto negativo, a perda do pensamento crítico, pois a reflexão tende a ser abolida das instituições universitárias.

Por fim, defende-se aqui a ideia de que a divulgação do conhecimento científico é um importante momento do ciclo da produção do conhecimento. No entanto, deve-se sempre ressaltar os cuidados a serem tomados com o que pode comprometer a qualidade do que é produzido e, principalmente, com a formação, saúde e futuro de quem produz ou irá produzir um dia.

\section{Resultados e discussão}

Esta seção apresenta, analisa e discute os resultados da pesquisa. Com base na análise temática dos dados, foram identificados seis temas, apresentados a seguir: produtivismo acadêmico na percepção dos discentes, quantidade versus qualidade, produção em colaboração, saúde, "prostituição acadêmica" e sistema mercadológico. 


\subsection{Produtivismo acadêmico na percepção dos discentes}

Com base na fala dos entrevistados, constatou-se que todos conhecem o termo produtivismo acadêmico - alguns apresentam definições e conceitos do termo. Em sua maioria, sustentam uma visão negativa do produtivismo acadêmico, como menciona o entrevistado 4: "Bom, quando se fala em produtivismo acadêmico, geralmente se fala em uma perspectiva ruim, nunca se fala de produtivismo acadêmico falando de algo bom, né? Então, esse termo tem uma conotação ruim, né?".

Contudo, o entrevistado ressalta também o lado positivo do produtivismo acadêmico. Para ele, o conhecimento produzido possibilita “[...] aproximar da sociedade, fazer com que a sociedade tenha mais disponibilidade de informações científicas, afinal, se a sociedade está tendo uma onda maior de informações não científicas, por que não acompanhar essa tendência, certo?”. Além disso, o produtivismo acadêmico pode servir para atender uma demanda social, uma vez que, mesmo não tendo "[...] uma qualidade maravilhosa, eles estão inserindo aquilo no debate científico, tu entende?".

Para alguns entrevistados há uma relação entre produtivismo acadêmico e obtenção de recursos financeiros. Para o entrevistado 6, a mensuração da produção científica visa aumentar a visibilidade de determinada área do conhecimento, pois, “[...] objetiva-se, com isso, aumentar os números para a obtenção de maiores recursos frente a agências de fomento e a verba do governo, [e também] por outras vias, [além de servir para a] justificação do governo para a aplicação dos recursos." (Entrevistado 6). Os fundos obtidos por meio das agências de fomento e governamentais são distribuídos a partir de avaliações feitas a cada três anos nos programas de pós-graduação. É com base nelas que os programas definem seus gastos e privilégios. De acordo com o entrevistado 9, "O sistema de avaliação que a gente tem talvez não seja adequado, [mas] é necessário, [e talvez por isso,] mereça ser repensado, porque o fato de você ter que produzir para justificar a existência do teu trabalho é complicado, né, porque você só é um aluno bom se você publica, né?" (Entrevistado 9). 
$\mathrm{Na}$ maioria dos casos, essa cobrança por publicar e produzir acaba gerando uma competitividade entre os discentes. Para o entrevistado 3, "A produção faz as pessoas competirem, e isso não é uma coisa tão boa.". Entretanto, ele considera essa competição necessária, pois “[...] faz as pessoas produzirem e fazer um crescimento para um determinado programa de pósgraduação...".

Por fim, o entrevistado 5 acredita que o produtivismo acadêmico serve para estimular ou pressionar os estudantes a publicar continuamente: " $E$ um processo pelo qual os setores da academia, da universidade, no caso, usam para estimular ou pressionar os estudantes a publicarem cada vez mais estudos científicos relacionados com a pesquisa que está a desenvolver nos programas de pós-graduação.” (Entrevistado 5). A pressão para aumentar as publicações levam os discentes a se questionarem acerca do que está em questão, "A quantidade ou a qualidade?".

\subsection{Quantidade versus qualidade}

Os discentes entrevistados apresentaram várias questões sobre a relação entre quantidade versus qualidade das publicações exigidas pela pós-graduação. Quando o discente participa de um processo de seleção na pós-graduação, uma parcela importante da "[...] sua nota final do processo seletivo é a quantidade que você produziu de artigos da sua área.”, coloca o entrevistado 1. Após o ingresso na pós-graduação, começam as exigências para a manutenção da bolsa e a pressão quanto às avaliações que o programa cobra. Essas publicações, no geral, acabam fragmentando o processo de geração do conhecimento: "Uma pessoa que publica cinco, dez artigos em um ano, é meio complicado, né, porque a gente sabe que [...] quanto mais publicações, o risco dessas publicações serem fragmentadas, fatiadas, é bastante grande." (Entrevistado 9).

O entrevistado 6 menciona que a pressão por produzir mais implica "em uma queda de qualidade do material produzido em favor do aumento do número de publicações”. Isso implica, conforme argumenta o entrevistado 4, na redução da "capacidade de refletir, [pois] ele precisa produzir, então, ele produz, ele 
produz, ele produz, ele produz e ele acaba não tendo aquele tempo para a reflexão que são os insights, as novas ideias. Então, ele acaba fazendo uma pesquisa mamão com açúcar, uma pesquisa que, na verdade, vai atender àquele objetivo, mas que não vai nada mais além disso, então, vai atender a essa demanda, mas não vai desenvolver a sociedade de uma melhor forma." (Entrevistado 4).

De modo geral, apesar dos discentes não concordarem com essa pressão por publicar, e acreditarem que a qualidade cai bastante quando se está preocupado com a quantidade, eles concordam que é necessário aderir a essas exigências do programa, pois são políticas e regras que não surgiram ali, mas "[...] são políticas das instituições que regulam o programa, né, CNPq, a própria CAPES, o Ministério da Educação. Então, essas políticas nos forçam a desorientar ou desfocar da formação, do exercício e do amadurecimento do pensamento científico, do exercício do amadurecimento da nossa intelectualidade, de como a gente lida com leitura, de como a gente lida com teorias. Então, o foco é retirado disso que é o propósito da formação. E onde é lançado o foco? O foco é lançado nisso, na produção.". Embora o entrevistado 6 acredite que essa pressão não é salutar, ela pode ser positiva, pois “[...] talvez. se eu não tivesse essa pressão, eu não tivesse produzido e ainda hoje eu não conseguiria escrever um artigo, como eu não conseguia no mestrado, como eu não consegui até sair do mestrado, né? Então, hoje eu consigo, já fiz alguns artigos.".

Embora a qualidade versus quantidade seja um assunto que possa gerar muita discussão, a maioria dos discentes considera que, sem a pressão por produzir, muitos não teriam publicado durante o período da pós-graduação. Por outro lado, eles também consideram que não adianta ter muita produção sem ter qualidade.

\subsection{Produção em colaboração}

Alguns entrevistados levantaram questões que envolvem a colaboração dos discentes com docentes e pesquisadores para a produção científica. Para alguns 
dos entrevistados, há anos, muitos artigos produzidos por discentes são publicados com o nome de seus orientadores, porém, conforme ressalta o entrevistado 7, "em muitas das produções, ele [o orientador] vai só como uma representação de orientador, mas, na realidade, quem escreve é o aluno”.

Essa posição é reforçada pelo entrevistado 6, pois, segundo ele, muita vezes, "[...] é transferida uma responsabilidade que é do professor para o discente - a responsabilidade de escrever. Então, ele vai escrever, ele vai pesquisar e o professor muitas vezes vai só assinar, só corrige, muitas vezes escreve o resumo, formata na revista, alguns artigos talvez existam até normas que é ser autor e o que é ser colaborador de uma pesquisa, mesmo você colaborando, você não é o autor, e isso é meio que ignorado, coloca em questão os aspectos éticos dentro da academia, produtivismo. Então, ele acaba pressionando os autores acadêmicos, e muitas vezes, passam por cima até de preceitos éticos, e acaba sobrecarregando o aluno, que fica impedido de fazer o fundamental, que é buscar a formação, o amadurecimento." (Entrevistado 6).

Esse aspecto da construção unilateral no processo de produção científica não é bem visto pelos entrevistados. Eles se dedicam a escrever artigos e outras formas de produção acadêmica e, por obrigação, têm de inserir o nome do orientador ou até mesmo de outro pesquisador sem que os mesmos tenham contribuído para a produção. Na visão do entrevistado 4, isso ocorre porque "[...] também tem produtivismo em cima do orientador, do quanto ele tem que produzir por ano. Ele tem que produzir tantos pontos por ano." (Entrevistado 4).

As questões levantadas pelos entrevistados remetem às diferenças entre colaboração científica e coautoria. Quando dois ou mais autores publicam um texto em conjunto, existe coautoria (KOSEOGLU, 2016). A colaboração científica ocorre quando pesquisadores trabalham em conjunto para "[...] alcançar o objetivo comum de produzir novos conhecimentos." (KATZ; MARTIN, 1997, p. 7). Portanto, para os entrevistados, parece injusto que haja coautoria sem uma efetiva colaboração científica. Sobre esse tema, o Código de Boas Práticas Científicas da FAPESP orienta que: 
[...] em um trabalho científico devem ser indicados como seus autores todos $\mathrm{e}$ apenas os pesquisadores que, tendo concordado expressamente com essa indicação, tenham dado contribuições intelectuais diretas e substanciais para a concepção ou realização da pesquisa cujos resultados são nele apresentados. (FUNDAÇÃO DE AMPARO À PESQUISA DO ESTADO DE SÃO PAULO, 2011, p. 23).

Apesar desse desequilíbrio no entendimento entre coautoria e colaboração científica, vários casos fogem desse padrão. Como ressaltam alguns dos entrevistados, muitos pesquisadores e docentes são altamente comprometidos e éticos com o seu trabalho.

\section{4 "Prostituição acadêmica"}

Em 2014, Moreno Barros defendeu a tese intitulada $O$ modelo brasileiro de governança acadêmica e seus efeitos na produtividade científica (BARROS, 2014). Nela, o autor discute o produtivismo recorrendo a Frey (2003), ao afirmar que o processo de produzir e publicar pelos estudantes torna-os, de um modo geral, prostitutas, uma vez que a prostituição está em omitir o próprio pensamento em favor de algo que se crê "mais publicável".

Essa lógica aparece no discurso dos entrevistados. Para o entrevistado 3, por exemplo, “[...] alguns programas de pós-graduação [...] vêm adotando critérios demais para a manutenção de bolsa, e para isso, o aluno tem que submeter pelo menos um artigo para uma revista para que ele possa garantir a bolsa dele. É como se fosse uma troca que tá vendendo, tá se vendendo." (Entrevistado 3).

Um dos entrevistados considera que o caminho da "prostituição acadêmica" não é compulsório, tampouco indispensável. O discente, apesar de estar em uma estrutura de poder assimétrica com o orientador e com o programa de pós-graduação, tem a possibilidade de estabelecer limites. O entrevistado 2 afirma que o termo "[...] prostituição é um pouco forte, [e diz entender o uso dessa terminologia, embora argumente que] você não faz nada com uma arma na sua cabeça, [você não está] com uma forca e alguém tá ali te colocando. Você escolhe essa vida e se ela não te agrada, você pode sair dela. Não é uma 
vida forçada, não é uma escolha forçada. Então, quando se trata de prostituição, eu fico me perguntando: tá, prostituição, então, só se a gente considerar essa prostituição como profissão. Então, é profissional, né, da prostituição por consentimento? Porque eu acho que a gente que se permite a entrar em fluxo de trabalho exacerbado e, por mais que se diga que tem uma questão de poder ali, se pode dizer não. Eu ainda acho que um depende do outro. A nossa profissão, os nossos orientadores, dependem da gente, nós dos nossos orientadores. O limite quem dá é a gente, ao meu ver." (Entrevistado 2).

A análise das entrevistas permitiu identificar alguns exemplos de "prostituição acadêmica", conforme relata o entrevistado 8: "Você vai ter que agradar o seu orientador, e aí você vai pegar cinco [...] artigos para produzir, mas nem todos têm relação com o seu tema de pesquisa. É uma prostituição no sentido de que você vai ter que fazer aquilo, porque você precisa indiretamente dessa produção, só que não tem nenhuma relação com o seu projeto, então, você acaba saindo da sua linha de pesquisa para produzir mais." (Entrevistado 8). Já o entrevistado 9 considera que: "A gente tá vendendo nosso tempo em troca de pontos, tempo de estudo, reflexão, leituras, para não perder bolsa, para não perder oportunidade, a gente precisa de pontos. Então, a gente acaba se prostituindo nesse sistema para poder fazer parte. É assim que funciona, infelizmente." (Entrevistado 9).

Para os entrevistados, em muitos casos, os discentes se veem obrigados a se "prostituir" em troca do aceite e publicação do que foi produzido e submetido a uma revista científica, para que tenham uma considerável quantidade de artigos produzidos e publicados. Além de maiores chances dentro dos programas de pós-graduação para a concorrência de bolsa de estudos, entre outros. Sendo assim, todo esse processo envolvendo a produção e a comunicação científica requer que princípios éticos sejam seguidos, a fim de que a troca de favores entre os membros da comunidade acadêmica não comprometa a qualidade do que se produz e se publica. 


\subsection{Saúde}

Nas últimas décadas ocorreram importantes transformações na economia, na política e, principalmente, na organização produtiva, que têm causado sérias consequências à saúde dos indivíduos. Diversos estudos apresentam relatos de impactos negativos do produtivismo acadêmico na saúde e na vida dos docentes e dos discentes que são avaliados pelas políticas institucionais quanto à sua produção científica, pois, para se manterem na academia, devem, obrigatoriamente, produzir.

Esses impactos são ressaltados pelo entrevistado 7: "Entendo porque também o questionamento das consequências causadas pelo produtivismo para com os professores, para com os docentes, porque eles também são cobrados. Mas, mais uma vez, eu repito [...], a gente não pode deixar de lembrar que os alunos também são cobrados, então, isso pode afetar muito a vida, dos discentes, trazendo muitas doenças, como é o caso de amigos que apresentaram no decorrer da pós-graduação sintomas de pânico, sintomas de depressão." (Entrevistado 7).

Para Zandoná, Cabral e Sulzbach (2014, p. 122), o sistema produtivista

[...] tem levado, de modo crescente, ao esquecimento do trabalhador como ser humano, com suas fraquezas e medos, ansiedades, bem como seus limites, contribuindo, dessa forma, para potencializar problemas de saúde física e mental e gerar sobrecarga emocional [...].

Como uma das características da Síndrome de Burnout, de acordo com Maslach e Jackson (1981), que dizem que a exaustão emocional leva o indivíduo a sensação de esgotamento.

O sistema produtivista tem alterado de maneira importante o significado da produção científica e aumentado o nível de estresse entre os discentes. Para o entrevistado 1, "Não é novidade que quem está na pós-graduação tá fazendo terapia, tá buscando tentar se ajudar de alguma forma, conversando com os colegas, vê que está todo mundo no mesmo barco: Nossa, não tô conseguindo escrever, tô bloqueada, tão me fazendo muita pressão." (Entrevistado 1). 
As exigências da academia, como o número de artigos a serem publicados e os prazos para a entrega de trabalhos, acabam sufocando os discentes, deixando-os preocupados e ansiosos, além de transformar a academia no palco principal de suas vidas. $\mathrm{O}$ entrevistado 4 afirma que, diante de todas essas cobranças, "Eu acabo ficando mais ansiosa, acabo ficando mais angustiada, eu acabo levando a academia como rumo central da minha vida que nem sempre é benéfico, eu acredito que não é. É uma característica que eu tenho tido para poder cumprir toda essa demanda, toda essa exigência ou toda essa tendência, então, eu fico bem frustrada." (Entrevistado 4).

Em síntese, a análise das entrevistas permitiu identificar a existência de uma lacuna quanto ao olhar das políticas institucionais em relação à saúde e bem-estar dos discentes e dos docentes que produzem na academia. Faltam políticas e iniciativas que contribuam para um processo de construção do conhecimento menos 'sofrido' e mais prazeroso.

\subsection{Sistema mercadológico de produção}

Esse novo modo de produção acadêmica contribuiu para o surgimento de uma cultura universitária centrada em uma lógica mercantil, que tende a transformar as universidades em prestadoras de serviços para o mercado (SILVA JUNIOR, 2005; SGUISSARDI; SILVA JUNIOR, 2009). De acordo com o discurso do entrevistado 4, a ciência pode ser concebida como "[...] um mercado que tem demandas. Assim como a indústria, que é um mercado que tem demandas, assim como é o comércio [...] que tem demandas, toda a questão das organizações, elas têm demandas que elas precisam." (Entrevistado 4). Patrus, Dantas e Shigaki complementam essa concepção quando afirmam que "[...] nesse sistema, vale o que é lido, o que é citado; em outras palavras, o que tem mercado." (2015, p. 6).

Essa concepção está presente no Programa de Pós-Graduação em Ciência da Informação (PPGCIN/UFSC). Segundo o entrevistado 10, "Recentemente, o programa de pós-graduação em Ciência da Informação revisou os parâmetros de cobrança, podemos dizer assim, por conta dos 
diversos cortes que tivemos no ano anterior na educação, e, consequentemente, as cobranças aumentaram. Antes, você deveria publicar um artigo, agora tem que, pelo menos, submeter um por ano em um periódico com qualis pelo menos B2, mas isso acontece apenas para quem tem bolsa, ou deseja manter. Porém, se você olha do ponto de vista do programa, uau!”.

Esse sistema mercadológico, com o passar do tempo, acaba trazendo consequências negativas para o desenvolvimento da produção do conhecimento. Ele impede "[...] que os estudantes pensem e desenvolvam suas ideias da melhor maneira e acabam trabalhando como se fizessem parte de uma linha de produção”, argumenta o entrevistado 10. A cobrança para publicar a qualquer custo acaba fazendo com que os discentes escrevam de qualquer maneira, ou seja, todo um caminho que deveria ser percorrido para a construção do conhecimento, não é seguido.

De acordo com o discurso dos entrevistados, é possível identificar que os mais afetados são os discentes bolsistas. Eles são considerados como "funcionários" dos programas de pós-graduação. Para o entrevistado 6, “[...] existe uma chantagem clara. Como no nosso curso de Ciência da Informação tem bastante gente que depende exclusivamente da bolsa, é um curso que é diferente de outros cursos como medicina, como direito, que o aluno tem uma tradição, tem uma história familiar que lhe permite outras formas de captar dinheiro e se manter na universidade. A gente não, a gente depende da bolsa, muitas vezes, é a única fonte, e muitas vezes, tem que ajudar outros familiares. Existe uma pressão de você produzir ou você vai perder a bolsa, e essa chantagem implica em uma pressão psicológica muito grande. Se eu não produzir o que vai ser de mim, né? E no próximo mês, eu preciso produzir, o que vai ser de mim no próximo semestre?" (Entrevistado 6).

A partir das entrevistas analisadas, evidencia-se que o Programa de PósGraduação em Ciência da Informação (PPGCIN/UFSC), no último ano, adotou normas para a manutenção das bolsas dos discentes, ao estabelecer critérios de publicações científicas em periódicos da área. Esse tipo de ação já existe em outros programas de pós-graduação no Brasil, cujo objetivo é aumentar seus 
conceitos e angariar recursos das agências de fomento e de outras instituições financiadoras.

\section{Considerações finais}

O objetivo deste estudo foi compreender a influência do produtivismo acadêmico na vida dos discentes de um curso de pós-graduação a partir de suas percepções.

Em primeiro lugar, os achados indicam que os entrevistados consideram os critérios de avaliação baseados na produtividade acadêmica importantes para o desenvolvimento da academia. Entretanto, chamam a atenção para a necessidade de rever a maneira como esses critérios estão sendo aplicados. A maioria acredita que não é preciso utilizar o termo "prostituição acadêmica", por se tratar de uma expressão muito forte para descrever o contexto do produtivismo acadêmico.

Em segundo, os cortes de verbas que ocorreram nos programas de pósgraduação nos últimos dois anos aprofundaram a posição produtivista e reforçaram os impactos negativos sobre os docentes e discentes: (1) aumentaram a competição entre docentes e entre discentes; (2) tornaram os critérios de avaliação dos discentes mais rigorosos (quem produz mais, consegue manter a bolsa de pesquisa); e (3) reduziram os prazos para a qualificação e defesa. Além disso, os cortes tiveram outros impactos não diretamente relacionados com o produtivismo acadêmico: estudantes tiveram suas bolsas de estudo cortadas; materiais essenciais de pesquisa foram reduzidos ou eliminados; projetos importantes não puderam ser realizados; e a constituição das bancas de mestrado e doutorado teve de ser reconfigurada por falta de recursos para passagem e hospedagem.

Em terceiro, com o produtivismo acadêmico, a ciência adquiriu um aspecto mercadológico prejudicial para o discente que passa a competir com outros colegas. Essa competição, de acordo com os entrevistados, não é saudável, pois acaba desencadeando problemas físicos e psicológicos. $\mathrm{Na}$ maioria das vezes, esses problemas são tratados com terapia, tornando-se, 
muitas vezes, recorrentes. Os distúrbios mais citados são os transtornos de ansiedade, depressão e síndrome do pânico.

Em quarto, para os entrevistados, a maneira como são efetuadas as cobranças do programa e do próprio orientador colocam os discentes sob forte pressão para produzir. $\mathrm{O}$ discente, como pesquisador em desenvolvimento, quer mostrar o seu melhor. Além dessas cobranças, contribui para o aumento da pressão as chamadas "atividades normais", tais como cursar as disciplinas obrigatórias e desenvolver a dissertação ou tese. Com essas pressões, se o discente não organiza sua agenda, acaba tendo resultados abaixo do exigido.

Já o quinto resultado desvela uma questão ética, visto que alguns entrevistados chamaram a atenção para a necessidade de incluir, nos artigos produzidos, os nomes de pessoas que não participaram efetivamente da construção do texto. Fica aparente nas entrevistas analisadas um conflito entre coautoria e colaboração científica.

Por fim, alguns entrevistados ressaltaram o lado positivo do produtivismo acadêmico, que os impele a aprender a escrever e a produzir artigos que são importantes para o meio acadêmico e profissional. Entretanto, é necessário que as políticas institucionais sejam revistas para incluir questões como a qualidade da produção acadêmica e o bem-estar dos autores.

\section{Financiamento}

Coordenação de Aperfeiçoamento de Pessoal de Nível Superior.

\section{REFERÊNCIAS}

BARATA, R. C. B. Dez coisas que você deveria saber sobre o Qualis. Revista Brasileira de Pós-Graduação, Brasília, v. 13, n. 30, p. 13-40, 2016.

BARROS, M. A. O modelo brasileiro de governança acadêmica e seus efeitos na produtividade científica. 2014. Tese (Doutorado em História das Ciências) - Universidade Federal do Rio de Janeiro, 2014.

BIANCHETTI, L. Os dilemas do coordenador de programa de pós-graduação: Entre o burocrático-administrativo e o acadêmico-pedagógico. In: BIANCHETTI, L; SGUISSARDI, V. Dilemas da pós-graduação em educação: gestão e avaliação. Campinas: Autores Associados, 2009. 
BIANCHETTI, L.; VALLE, I. R. Produtivismo acadêmico e decorrências às condições de vida/trabalho de pesquisadores brasileiros e europeus. Ensaio: Avaliação e Políticas Públicas em Educação, Rio de Janeiro, v. 22, n. 82, p. 89110, jan./mar., 2014.

BRASIL. Coordenação de Aperfeiçoamento de Pessoal de Nível Superior.

História e missão. 2017. Disponível em: <https://www.capes.gov.br/historia-emissao>. Acesso em: 3 nov. 2017.

BRASIL. Coordenação de Aperfeiçoamento de Pessoal de Nível Superior.

Qualis. 2018. Disponível em:

<https://sucupira.capes.gov.br/sucupira/public/index.xhtml>. Acesso em: 3 nov. 2017.

BREMBS, B. Prestigious science journals struggle to reach even average reliability. Frontiers in Human Neuroscience, Lausana, v. 12, n. 37, p. 1-7, 2018.

CASTANHA, R. C. G.; GRÁCIO, M. C. C. Contribuição da análise multivariada para os indicadores de avaliação dos programas de pós-graduação: uma análise na área de matemática (2007-2009). Em Questão, Porto Alegre, v. 21, n. 1, p. 130-149, 2014.

CHAUÍ, M. A universidade pública sob nova perspectiva. Revista Brasileira de Educação, São Paulo, n. 24, p. 5-15, 2003.

DOMINGUES, E. Autoria em tempos de "produtivismo acadêmico". Psicologia em Estudo, Maringá, v. 18, n. 2, p. 195-198, 2013.

FONSECA, C. Avaliação dos programas de pós-graduação: do ponto de vista de um nativo. Horizontes Antropológicos, Porto Alegre, v. 7, n. 16, p. 261-275, 2001.

FREITAS, L. G. (Org.). Prazer e sofrimento no trabalho docente: pesquisas brasileiras. Curitiba: Juruá Psicologia, 2013.

FREY, B. Publishing as prostitution?: choosing between one's own ideas and academic success. Public Choice, Logan, v.116, n.1-2, p. 205-206, 2003.

FUNDAÇÃO DE AMPARO À PESQUISA DO ESTADO DE SÃO PAULO. Código de boas práticas científicas. São Paulo: FAPESP, 2011.

GATTI, B. A. Reflexão sobre os desafios da pós-graduação: novas perspectivas sociais, conhecimento e poder. Revista Brasileira de Educação, São Paulo, n. 18, p. 108-116, 2001.

GODOI, C.; XAVIER, W. O produtivismo e suas anomalias. Cadernos EBAPE.BR, Rio de Janeiro, v. 10, n. 2, p. 456-465, 2012. 
HILL, D. O neoliberalismo global, a resistência e a deformação da educação. Currículo sem Fronteiras, [S.1.], v. 3, n. 2, p. 24-59, 2003.

JAPIASSÚ, H.; MARCONDES, D. Dicionário de Filosofia. 3. ed. Rio de Janeiro: Jorge Zahar, 2001.

KATZ, J. S.; MARTIN, B. R. What is research collaboration? Research Policy, Amsterdam, n. 26, p. 1-18, 1997.

KOSEOGLU, M. A. Growth and structure of authorship and co-authorship network in the strategic management realm: evidence from the Strategic Management Journal. Business Research Quarterly, Ankara, p.153-170, 2016.

KUNZ, E. Pós-graduação em Educação Física no Brasil: o fenômeno da hiperprodutividade e formação cultural. Revista Kinesis, Santa Maria, v. 30, n. 1, p. 1-13, 2012.

LEITE, F. C. L. Gestão do conhecimento científico no contexto acadêmico: proposta de um modelo conceitual. 2006. Dissertação (Mestrado em Ciência da Informação) - Universidade de Brasília, Brasília, 2006.

LUZ, M. T. Prometeu acorrentado: análise sociológica da ategoria produtividade e as condições atuais da vida acadêmica. PHYSIS: Revista de Saúde Coletiva, Rio de Janeiro, v. 15, n.1, p. 39-57, 2005.

MACHADO, A. M. N. Políticas que impedem o que exigem: dimensões controvertidas na avaliação da pós-graduação brasileira. Universidade e Sociedade, Brasília, v. 39, p. 137-149, 2007.

MASLACH, C.; JACKSON, S. E. Maslach burnout inventory. Palo Alto: Consulting Psychologists Press, 1981.

MEADOWS, A. J. A comunicação científica. Brasília: Briquet de Lemos, 1999.

MINAYO, M. C. S. O desafio do conhecimento: pesquisa qualitativa em saúde. São Paulo: HUCITEC, 2007.

MINAYO, M. C. S. Trabalho de campo: contexto de observação, interação e descoberta. In: MINAYO, M. C. de S.; DESLANDES, S. F; GOMES, R.

Pesquisa social: teoria, método e criatividade. 29. ed. Petrópolis: Vozes, 2010.

MOREIRA, A. F. A. A Cultura da performatividade e a avaliação da PósGraduação em Educação no Brasil. Educação em Revista, Belo Horizonte, v. 25, n. 3, p. 23-42, 2009.

MOTA, I. D. et al. Síndrome de Burnout em estudantes universitários: um olhar sobre as investigações. Motrivivência, Florianópolis, v. 29, n. esp., p. 243-256, 2017. 
MUELLER, S. P. M. Literatura científica, comunicação científica In: TOUTAIN, L. M. B. B. (Org.). Para entender a Ciência da Informação. Salvador: EDUFBA, 2007.

NASCIMENTO, L. F. Modelo Capes de avaliação: quais as consequências para o triênio 2010-2012? Administração: ensino e pesquisa, Rio de Janeiro, v. 4, n. 11, p. 579-600, 2010.

PATRUS, R.; DANTAS, D. C.; SHIGAKI, H. B. O produtivismo acadêmico e seus impactos na pós-graduação stricto sensu: uma ameaça à solidariedade entre pares? Cadernos EBAPE.BR, Rio de Janeiro, v. 13, n. 1, jan./mar. 2015.

RICCI, R. A peculiar Produção Intelectual do Brasil recente. Revista Espaço Acadêmico, Maringá, v. 9, n. 100, p. 16-22, 2009.

SANTOS, A. R. Metodologia científica: a construção do conhecimento. 3. ed. Rio de Janeiro: DP\&A, 2000.

SGUISSARDI, V. Produtivismo acadêmico. In: Oliveira, D. A.; Duarte, A.; Vieira, L. (Org.). Dicionário de trabalho, profissão e condição docente. Belo Horizonte: Faculdade de Educação UFMG, 2010.

SGUISSARDI, V.; SILVA JUNIOR, J. R. Trabalho intensificado nas federais: pós-graduação e produtivismo acadêmico. São Paulo: Xamã, 2009.

SHELTON, B. A.; AGGER, B. Academic time and motion in an age of accountability: The degradation of intellectual life. The New York Journal of Sociology, New York, v. 3, n. 1, 2010.

SILVA, J. V. P.; SILVA, L. L.; MOREIRA, W. W. Produtivismo na pósgraduação. Nada é tão ruim, que não possa piorar. É chegada a vez dos orientandos! Movimento, Porto Alegre, v. 20, n. 4, p. 1423-1445, out./dez. 2014.

SILVA JUNIOR, J. R. Pragmatismo e populismo na educação superior nos governos FHC e Lula. São Paulo: Xamã, 2005.

TARGINO, M. G. Comunicação científica: uma revisão de seus elementos básicos. Informação \& Sociedade, João Pessoa, v. 10, n. 2, p. 37-85, 2000.

TAYLOR, S. J.; BOGDAN, R. Introduction to qualitative research methods. 3. ed. New York: John Wiley \& Sons, 1998.

TREIN, E.; RODRIGUES, J. O mal-estar na academia: produtivismo científico, o fetichismo do conhecimento mercadoria. Revista Brasileira de Educação, São Paulo, v. 16, n. 48, p. 769-819, 2010.

UNIVERSIDADE FEDERAL DE SANTA CATARINA. Programa de PósGraduação em Ciência da Informação. Área de concentração. 2017. Disponível 
em: <http://pgcin.paginas.ufsc.br/area-de-concentracao/>. Acesso em: 3 nov. 2017.

ZANDONÁ, C.; CABRAL, F. B.; SULZBACH, C. C. Produtivismo acadêmico, prazer e sofrimento: um estudo bibliográfico. Perspectiva, Erechim. v. 38, n. 144, p. 121-130, dez. 2014.

\title{
Academic productivism in the lives of graduate students
}

\begin{abstract}
Academic productivism is a phenomenon characterized by excessive appreciation of quantity and little consideration of the quality of academic production. The objective of this article is to understand the influence of academic productivism in the life of students of a graduation course based on their perceptions. The study used the qualitative method substantiated on indepth interviews and data thematic analysis. Ten students were interviewed. The students consider academic productivism both positive and negative. From the positive point of view, they argue that the charge for producing contributes to the process of building knowledge, and on the negative side, the pressure to publish in quantity requires intense dedication, generating, in many cases, psychological, emotional and physical problems.
\end{abstract}

Keywords: Academic productivism. Graduate studies. Scientific production. Students.

Recebido: 29/12/2017

Aceito: 28/03/2018 